E3S Web of Conferences 1, 26004 (2013)

DOI: $10.1051 / \mathrm{e} 3$ sconf/20130126004

(C) Owned by the authors, published by EDP Sciences, 2013

\title{
Metals as biomarkers of the environmental human exposure
}

\author{
B. Bocca, A. Pino ${ }^{1}$ and A. Alimonti \\ ${ }^{1}$ Department of Environmental and Primary Prevention, Istituto Superiore di Sanità, Rome 00161, ITALY
}

\begin{abstract}
The $1^{\text {st }}$ PROBE programme for the assessment of the internal dose of metals of the Italian population closed in 2011. A population sample of 1423 individuals, aged between 18 and 65 years from five regions, are recruited and information on gender, age and lifestyles of subjects is collected by a questionnaire. Concentrations of 20 metals, namely As, Be, Cd, Co, Cr, Hg, Ir, Mn, Mo, Ni, Pb, Pd, Pt, Rh, Sb, Sn, Tl, U, V and $\mathrm{W}$ are determined by the sector field inductively coupled plasma mass spectrometry (HR-ICP-MS) in whole blood and serum. Metals levels are reported as geometric means (GM) and $95^{\text {th }}$ percentiles (P95). Biomarkers variations in sub-groups of the population stratified for influencing variables are also assessed. A comparison with available guideline values for some biomarkers of exposure $(\mathrm{Cd}, \mathrm{Co}, \mathrm{Hg}$ and $\mathrm{Pb}$ in human blood) and the levels determined in the Italian population are also outlined.
\end{abstract}

Key words: human biomonitoring, metals, reference values, internal dose

\section{Introduction}

In Italy, a national biosurveillance programme (PROBE, PROgramme for Biomonitoring the Italian population Exposure) capable of assessing human exposure to metals of toxicological significance and of particular environmental persistence started in 2008. Through this biomonitoring campaign, the adult Italian population exposure to 20 priority metals, namely $\mathrm{As}, \mathrm{Be}, \mathrm{Cd}, \mathrm{Co}$, $\mathrm{Cr}, \mathrm{Hg}, \mathrm{Ir}, \mathrm{Mn}, \mathrm{Mo}, \mathrm{Ni}, \mathrm{Pb}, \mathrm{Pd}, \mathrm{Pt}, \mathrm{Rh}, \mathrm{Sb}, \mathrm{Sn}, \mathrm{Tl}, \mathrm{U}, \mathrm{V}$ and $\mathrm{W}$, has been defined by the direct measurement of their concentration in blood and serum, representing an integrated estimation of the different exposure sources (air, water, soil, diet, and consumers products) and contributing also to the knowledge of individual susceptibility to metals (as a function of age, sex and lifestyles).

\section{Materials and Methods}

The PROBE population consisted of 1423 adults residents in five Italian regions (south, central and north of Italy), aged between 18 and 65 years (41\% between 36 and 50 years), $67 \%$ of men and $33 \%$ of women, $60 \%$ of nonsmokers and $17 \%$ of smokers, and an equal percentage of consumers and non consumers of alcohol. The PROBE survey used a program to collect information on: i), the subject's general characteristics (gender, age, height, weight, body mass index); ii), history (acute or chronic intake of medications and/or supplements, change in body weight, dental fillings or prostheses, etc..); iii), lifestyle (alcohol consumption, smoking, exercise) and environment (car traffic at home and at work, type of industrial area nearby); iv), and diet (Alimonti et al., 2011). Laboratory measurements underwent an extensive quality control including tolerance limits for operational parameters, method validation and the calculation of measurements uncertainty. The metal analysis was performed by the sector field iInductively coupled plasma mass spectrometry (HR-ICP-MS) after microwave digestion of blood samples and water-dilution of serum samples (Bocca et al. 2010, 2011).

\section{Results and Discussion}

Metal levels as geometric means (GM) and $95^{\text {th }}$ percentiles (P95) are reported in Table 1.

For each metal, the GM represents an indicator of central tendency and the P95 is the value below which lies the $95 \%$ of the Italian population. This last value corresponds to the so called reference value (RV) that can be used as background value for comparisons with higher exposure scenarios and for developing exposure restrictions and prevention strategies.

Regarding the data interpretation, it should be highlighted that a metal concentration higher than the P95 found in people' blood and/or serum does not mean that the metal causes disease. Some international bodies have established limit values for a few biomarkers of exposure 
Table 1. Levels of metal biomarkers in the Italian population.

\begin{tabular}{|c|c|c|c|}
\hline Metal & Fluid & GM & P95 \\
\hline As & blood & 1.14 & 5.32 \\
\hline $\mathrm{Be}$ & blood & 0.08 & 0.18 \\
\hline $\mathrm{Cd}$ & blood & 0.53 & 1.42 \\
\hline Co & blood & 0.15 & 0.44 \\
\hline $\mathrm{Cr}$ & blood & 0.24 & 1.09 \\
\hline $\mathrm{Hg}$ & blood & 1.19 & 5.16 \\
\hline Ir* & serum & 2.46 & 7.05 \\
\hline $\mathrm{Mn}$ & blood & 8.19 & 14.5 \\
\hline Mo & blood & 1.21 & 2.05 \\
\hline $\mathrm{Ni}$ & serum & 0.35 & 0.94 \\
\hline $\mathrm{Pb}$ & blood & 19.9 & 51.7 \\
\hline $\mathrm{Pd}^{*}$ & serum & 10.6 & 29.4 \\
\hline $\mathrm{Pt}^{*}$ & serum & 5.23 & 13.3 \\
\hline $\mathrm{Rh}^{*}$ & serum & 9.28 & 23.1 \\
\hline $\mathrm{Sb}$ & blood & 0.31 & 0.72 \\
\hline $\mathrm{Sn}$ & blood & 0.54 & 2.25 \\
\hline $\mathrm{Tl}$ & blood & 0.037 & 0.098 \\
\hline $\mathrm{U}$ & blood & 0.006 & 0.014 \\
\hline V & serum & 0.044 & 0.11 \\
\hline W & blood & 0.028 & 0.075 \\
\hline
\end{tabular}

*ng/L

(Cd, $\mathrm{Co}, \mathrm{Hg}$ and $\mathrm{Pb}$ in human blood) with which to compare and interpret human biomonitoring data. In particular, the US EPA (Environmental Protection Agency) has identified the biological equivalents (BEs), which identifies a priority case for further investigations rather than to imply an effect on human health. Moreover, the US ACGIH (American Conference of Governmental Industrial Hygienists) has identified the biological exposure indices (BEIs) for exposed workers that indicate the extent of exposure but are not directly related to effects on health. Differently from the above cited limits, the human biomonitoring values known as HBM-II purchased by the German Commission for Human Biomonitoring provide levels above which an adverse effect on human health is associated.

The number of PROBE cases exceeding the the aforesaid biological limits is shown in Table 2 .
Table 2. Biological guideline values in $\mu \mathrm{g} / \mathrm{L}$ and number of subjects higher (n).

\begin{tabular}{lllllll}
\hline & BE & $\begin{array}{l}n \\
>\text { BE }\end{array}$ & BEI & $\begin{array}{l}n \\
>\text { BEI }\end{array}$ & HBMII & $\begin{array}{l}\text { n } \\
>\text { HBMII }\end{array}$ \\
\hline $\mathrm{Cd}$ & 1.7 & 37 & 5 & 0 & & \\
\hline $\mathrm{Co}$ & \multicolumn{1}{l}{} & & 9 & & \\
\hline $\mathrm{Hg}$ & & & 15 & 1 & 15 & 1 \\
\hline $\mathrm{Pb}$ & & & 300 & 0 & 150 & 3 \\
\hline
\end{tabular}

Data illustrate how the $2.6 \%$ of the population had $\mathrm{Cd}$ levels greater than the $\mathrm{BE}$, although these results do not involve a risk to health. With regard to Co only the $0.6 \%$ of the entire studied population shows values above the BEI, but also in this case the values are not conclusive for a risk characterization. On the contrary, 1 subject and 3 subjects out of 1420 show levels of $\mathrm{Hg}$ and $\mathrm{Pb}$ respectively higher than the HBMII values and for such subjects can be assumed an exposure associated with a health effect. For these subjects additional blood evaluation would be provided in order to better clarify the exposure scenario and influencing factors (individual and/or susceptibility)..

Considering the questionnaire data on the characteristics and habits of subjects, the variations in metals as a function of gender (G), age (A), smoking (S) and alcohol consumption (AC) are reported in the Table 3.

Table 3. Biomarkers variations as a function of gender (G), age (A), smoking (S) and alcohol consumption (AC)

\begin{tabular}{|c|c|c|}
\hline Metal & Fluid & Variable : effect \\
\hline $\mathrm{Cd}$ & blood & $\mathrm{S}$ : higher in smokers \\
\hline Co & blood & G: higher in women \\
\hline $\mathrm{Hg}$ & blood & G: higher in men \\
\hline $\mathrm{Ir}$ & serum & A: decreases with age \\
\hline Mn & blood & AC: increases with alcohol \\
\hline $\mathrm{Pb}$ & blood & $\begin{array}{l}\text { G. A. S. AC: } \\
\text { higher in men, in smokers and } \\
\text { increases with alcohol and age }\end{array}$ \\
\hline $\mathrm{Pd}$ & serum & $\begin{array}{l}\text { G. A: higher in men and } \\
\text { increases with age }\end{array}$ \\
\hline $\mathrm{Rh}$ & serum & G: higher in women \\
\hline $\mathrm{U}$ & blood & A: decreases with age \\
\hline $\mathrm{V}$ & serum & G: higher in women \\
\hline W & blood & $\begin{array}{l}\text { G. A: higher in men } \\
\text { and decreases with age }\end{array}$ \\
\hline
\end{tabular}




\section{Conclusion}

The PROBE programme has identified and analyzed a large profile of environmental metals in the human body in an attempt to define a characteristic pattern for adult residents in Italy. The data produced should facilitate comparison studies to identify exposure to the toxic metal higher than the reference values reported.

\section{Acknowledgements}

This study was financially supported by the Project 347 PROBE 8M/29, 2008-2010 (Italian Ministry of 348 Health).

\section{References}

Alimonti A, Bocca B, Mattei D, Pino A. Programme for biomonitoring the italian population exposure (PROBE): internal dose of metals. 2011, ix, 83 p. Rapporti Istisan 11/9.

Bocca B, Mattei D, Pino A, Alimonti A. Uncertainty evaluation in the analysisi of biological sample by sector field inductively coupled plasma mass spectrometry. Part A: measurements of $\mathrm{Be}, \mathrm{Cd}, \mathrm{Hg}$, $\mathrm{Ir}, \mathrm{Pb}, \mathrm{Pd}, \mathrm{Pt}, \mathrm{Rh}, \mathrm{Sb}, \mathrm{U} \mathrm{Tl}$ and $\mathrm{W}$ in human serum. Rapid Commun Mass Spectrom 2010; 24; 2363-9.

Bocca B, Mattei D, Pino A, Alimonti A. Uncertainty evaluation in the analysisi of biological sample by sector field inductively coupled plasma mass spectrometry. Part B: measurements of As, Co, Cr, $\mathrm{Mn}, \mathrm{Mo}, \mathrm{Ni}, \mathrm{Sn}$ and $\mathrm{V}$ in human serum. Rapid Commun Mass Spectrom 2011; 25; 453-8. 